\title{
Correlates of HIV Testing among African American and Latino Church Congregants: The Role of HIV Stigmatizing Attitudes and Discussions about HIV
}

\author{
Laura M. Bogart, Kathryn Pitkin Derose, David E. Kanouse,
} Beth Ann Grifin, Ann C. Haas, and Malcolm V. Williams

\begin{abstract}
Faith-based organizations can be key settings in which to reach African Americans and Latinos for HIV prevention, but little is known regarding factors that predict congregants' HIV testing behaviors. We examined the extent to which sociodemographic factors, HIV-related cues to action (e.g., knowing someone who is HIV-positive), and the social climate surrounding HIV (stigma toward a bypothetical HIV-positive congregant, HIV-related discussions at church about abstinence, condoms, and testing) were associated with willingness to be tested in church and with ever having been tested among 1211 African American and Latino congregants. Multivariate analyses indicated that congregants were more open to church-based testing if they were younger and had discussed condoms at church. They were less open if they expressed stigmatizing attitudes toward a bypothetical congregant. Foreign-born Latinos with low English proficiency were more willing to be tested at church than were African Americans. Congregants were more likely to have ever been tested if they were younger, African American, female, or married; if they knew someone who was HIV-positive; and if they had discussed testing and condoms at church. They were less likely if they had discussed abstinence. Open dialogue around HIV may activate congregants to be more receptive to church-based prevention.
\end{abstract}

KEYWORDS African American/Black, Faith-based organizations, HIV/AIDS, HIV testing, Latino/Hispanic

\section{INTRODUCTION}

Of the estimated 1.2 million people living with HIV in the USA, about $20 \%$ are not aware of their positive serostatus, ${ }^{1}$ with an estimated $19 \%$ of African Americans and $20 \%$ of Latinos living with HIV not diagnosed, versus $15 \%$ of Whites. ${ }^{2}$ Moreover, African Americans and Latinos are more likely than Whites to be diagnosed with advanced stages of HIV. ${ }^{3}$ These disparities in diagnosis may be a result of access to and acceptance of HIV testing. To increase the number of people who know their status, in 2006, the Centers for Disease Control and Prevention recommended routine testing in healthcare settings for all adolescents and adults. ${ }^{4}$ However, routine testing often does not reach people who have less access to the healthcare system or who are less engaged in healthcare-in part due to high levels

Bogart is with the Harvard Medical School and Boston Children's Hospital, Boston, MA, USA; Derose, Kanouse, Grifin, Haas, and Williams are with the RAND Corporation, Santa Monica, CA, USA; Bogart is with the Boston Children's Hospital, Division of General Pediatrics, 300 Longwood Avenue, Boston, MA 02115, USA.

Correspondence: Laura M. Bogart, Harvard Medical School and Boston Children's Hospital, Boston, MA, USA. (E-mail: laura.bogart@childrens.harvard.edu) 
of medical mistrust in general and specifically related to HIV, especially in African American communities. ${ }^{5-9}$ Finding effective ways to bring routine testing to community-based settings, especially ones that are trusted and seen as credible to community members, is thus essential to reduce undiagnosed infection.

HIV testing has been associated with several psychosocial and behavioral factors in general US population samples, including greater perceived HIV risk, greater behavioral risk, and lower fear of HIV stigma; ${ }^{10-14}$ sociodemographic factors related to greater testing include African American and Latino (versus White) race/ ethnicity and older age. ${ }^{12,15-18}$ Among African Americans specifically, having had an HIV test has been associated with female gender, ${ }^{19}$ being widowed or separated (vs. married), ${ }^{20}$ prior diagnosed sexually transmitted infection, ${ }^{19,21}$ recent healthcare utilization, ${ }^{22}$ healthcare provider recommendation, ${ }^{22}$ and being US-born (vs. foreign-born). ${ }^{23}$ In qualitative research, African Americans suggested that specific cues to action (i.e., a stimulus, such as an experience, that triggers the decision to change health behaviors ${ }^{24}$ ), including knowing someone living with HIV and perceiving high personal HIV risk from past behaviors, may lead to a greater readiness for HIV testing. ${ }^{25}$ In addition, HIV testing may be impeded by greater perceptions of HIV stigma, for example, because individuals may fear that people who are not accepting of HIV would discriminate against them if they are found to be seropositive. ${ }^{25}$

Among Latinos, prior HIV testing has generally been associated with female gender, ${ }^{20,26}$ higher education level, ${ }^{26-28}$ higher income, ${ }^{26}$ older age, ${ }^{20,27}$ being divorced (vs. married), ${ }^{20}$ and recent or regular healthcare utilization. ${ }^{28-30}$ Lack of testing is associated with undocumented residency status and being foreignborn, ${ }^{26,31}$ perhaps because of a reluctance to interact with formal systems such as healthcare or concern about being reported to government officials. ${ }^{29,32}$ In addition, Latinos who perceive greater benefits (e.g., to one's community and family) and expect fewer negative consequences (e.g., anticipated HIV stigma) have been shown to have higher intentions to be tested. ${ }^{33}$

Because African Americans and Latinos (especially those who are immigrants) are less likely to use healthcare regularly than are Whites, ${ }^{34,35}$ bringing HIV testing to community settings where African Americans and Latinos gather may help to reduce disparities in diagnosis rates. Faith-based organizations, including churches and other types of congregations, have been proposed as ideal settings in which to reach African American and Latino populations for health promotion. ${ }^{36}$ Churches, which tend to be trusted institutions within their communities, frequently provide social services to congregants and local community members through formal or informal programs (e.g., pastoral care, HIV education/workshops). ${ }^{37}$ Many churches are located in urban areas and serve minority communities with high levels of poverty $^{38}$ — characteristics generally related to higher HIV prevalence. ${ }^{39,40}$ Thus, church-based HIV prevention interventions have the potential to reach at-risk members of underserved communities. Nevertheless, congregational surveys suggest that, although most faith-based organizations are involved in health promotion programs, few are engaged in HIV-related activities specifically. ${ }^{41}$

Little is known regarding what individual factors predict uptake of HIV testing among church congregants, or how church-based efforts can help to promote HIV testing. One prior study examined correlates of prior HIV testing among African American church congregants, finding that not having insurance and condom use were associated with ever being tested for HIV, and unmarried marital status and intentions to get tested were associated with being tested in the last 12 months. ${ }^{42}$ 
Several sociodemographic and HIV-related variables, including age, gender, education, income, number of sexual partners, HIV stigma, and HIV knowledge were not significantly related to ever having been tested for HIV in that study.

Although prior research has elucidated some of the factors that could help to promote HIV testing among congregants, almost no research has examined the social climate surrounding HIV in the church setting, and none to date has included Latino congregants. For example, factors related to the church's social context around HIV, including levels of stigmatizing attitudes in the congregation around people living with HIV, and whether HIV is openly discussed among members of the congregation, may influence members' comfort with testing in their own church or in general. Although prior research has not examined the relationship between HIV stigma in a faith-based setting and HIV testing, research suggests that HIV stigma can lead to reluctance to test for HIV because of the fear that others will mistreat people who have a seropositive result. $^{25}$ Further, to our knowledge, only one prior study has assessed comfort with discussion of HIV-related topics in church. Results indicated that feeling supported by one's congregation and going to a church with ministries that helped people with their problems were associated with comfort discussing HIV prevention and treatment in church. ${ }^{43}$ Other research has examined communication about HIV in non-faith-based, high-prevalence settings, finding that individuals seek out social sources of information about HIV via informal conversations with social network members in order to assess their own personal risk. ${ }^{44,45}$ These studies did not directly examine HIV-related discussions and HIV testing behaviors, although they suggest that such discussions may prompt individuals to engage in preventive behaviors.

In the present study, we explored the extent to which sociodemographic factors, HIV-related cues to action (i.e., HIV risk behaviors, knowing someone with $\mathrm{HIV}^{46,47}$ ), and the church-related social climate surrounding HIV (i.e., discussions around HIV at church, stigmatizing attitudes about congregants with HIV) were related to willingness to be tested for HIV in a church setting and with ever having been tested. Because stigmatizing attitudes related to HIV and discussions about HIV in the church milieu have received little prior research attention, we explored the extent to which these factors were significantly associated with the HIV testing outcomes, above the effects of individual-level sociodemographic factors that have been shown to significantly predict HIV testing in prior research.

\section{METHODS}

\section{Setting}

This research was conducted in the context of a pilot intervention study to reduce HIV stigma and increase HIV testing, called the Facilitating Awareness to Increase Testing for HIV (FAITH) Project. ${ }^{48}$ Churches were recruited for the study from Long Beach, CA and surrounding areas. Long Beach has a cumulative incidence rate of 1359 AIDS cases per 100,000 residents (from 1981 through December 31, 2012). ${ }^{49}$ Because African Americans and Latinos are disproportionately affected by HIV in the USA, ${ }^{50}$ we recruited churches that primarily served African American or Latino congregants. 


\section{Community Engagement}

Community stakeholders were engaged throughout all study phases in a community advisory board $(\mathrm{CAB})$ that included local religious and public health leaders. Members of the church leadership at each study church were actively involved in determining how to integrate the research into their setting.

\section{Church Selection}

Our sampling frame included all 61 African American and Latino churches in Long Beach and adjacent areas that could be enumerated through local faithbased and telephone directories and $\mathrm{CAB}$ contacts. Eligibility criteria included: $>70 \%$ African American or Latino, $\geq 100$ typical Sunday attendance, and almost no HIV-related activities (e.g., programs, services, and outreach) conducted at the church previously (based on a free listing by church leadership of HIV-related activities). Specifically, the church leadership was asked a general question about health-related activities (i.e., "What kinds of health-related activities has your church done recently or in the past?"), with specific probes to capture HIVrelated activities (e.g., "Which health issue or topic do/did you address?"; "Has your church ever been involved in any type of HIV/AIDS-related activity, service, program or outreach?”).

We conducted a telephone screening survey of all 61 churches; 33 (54\%) completed the screener (five refused and 23 never responded), and of these, 11 (five African American; six Latino) were considered eligible for the study. Of the 33 churches that completed the screening interview, 20 screeners were done by pastors and 13 by other church staff. Eligible churches were matched on race/ethnicity, denomination, and congregation size, with one pair selected for each type (mediumsized African American Baptist, small Latino Pentecostal, large Latino Catholic). Of the 11 churches, six churches were invited to participate in the study, consistent with available resources and the need to match church pairs on race/ethnicity, denomination, and size; the pastors of each of these six churches were sent letter requests for a meeting with project staff, followed by in-person meetings at the respective churches by project staff. One congregation refused and five agreed, leaving a sample of two medium-sized African American Baptist churches, two small Latino Pentecostal churches, and one large Latino Catholic church. Churches were given honoraria totaling $\$ 1500$ ( $\$ 500$ to church, $\$ 500$ to pastor, and $\$ 500$ to the designated church coordinator). Only the baseline data from the study are presented in this manuscript.

\section{Procedure}

The assessment procedures and survey items were pretested in one Latino and one African American church and refined in collaboration with church leadership prior to administration for the present study. The survey was designed to be selfadministered (in English or Spanish) and conducted in group settings at times when congregants normally came to church (e.g., group meetings, after religious services). Church congregants were recruited for group survey administration by church staff and volunteers, who distributed recruitment flyers and made announcements at meetings and church services. For confidentiality reasons, church staff and volunteers were not involved in the actual administration of the survey (including consent processes and handling of completed questionnaires).

Group survey sessions were conducted over several weeks, in church rooms, with each respondent having a separate area (note that one African American church 
preferred to have a "take-home" survey approach whereby surveys were distributed after services and returned in sealed envelopes). Bilingual research assistants were available during group administration sessions to answer questions. Survey administrators distributed consent materials, went through an oral consent process with the group, answered questions, and collected completed and placed surveys in lock-boxes immediately after each session. To maintain confidentiality, participants did not provide personal identifiers. The response rate was estimated at $73 \%$ of regular church attendees at the time of the survey. Participants received a $\$ 20$ gift card and refreshments for participation. All procedures were approved by the RAND Human Subjects Protection Committee.

\section{Assessment}

HIV Testing-Related Outcomes. Participants were asked about their willingness to get tested in church with one item adapted from prior research ${ }^{51}$ : "Would you get tested for HIV if it was available through your church in a private and confidential setting?" with response options $1=$ definitely no, 2 = probably no, 3 = probably yes, and 4 =definitely yes. Participants also reported their HIV testing history by responding to the item, "Have you ever been tested for HIV, the virus that causes AIDS?”

Predictors: Sociodemographic Characteristics. Participants reported their gender, age, race/ethnicity, highest level of education $(1=6$ th grade or less to $7=$ some graduate school or graduate degree), employment status (yes/no), marital status (categorized as single, married, living with partner, and divorced, separated, or widowed), household income (\$9999 or less; $\$ 10,000-\$ 19,999 ; \$ 20,000-\$ 29,999$; $\$ 30,000-\$ 39,999 ; \$ 40,000-\$ 49,999 ; \$ 50,000-\$ 59,999 ; \$ 60,000-\$ 69,999$; $\$ 70,000-\$ 99,999 ; \$ 100,000$ or more), and type of medical insurance (public, private, none, or other). Participants also reported number of years that they lived in the USA (dichotomized into US-born, i.e., lived in the USA for whole life, vs. foreignborn), and English proficiency (i.e., how well they spoke English from 1, not at all to 4 , very well).

Because race/ethnicity, nativity, and English-language fluency were all highly correlated, we created four mutually exclusive groups combining the variables for inclusion in the regression models: African Americans (reference group); US-born Latinos who reported speaking English "well" or "very well"; foreign-born Latinos who reported speaking English "well” or "very well”; and foreign-born Latinos who reported speaking English "not well” or "not at all."

Predictors: HIV-Related Cues to Action. We assessed whether participants knew anyone with HIV or AIDS using the following item: "Do you know anyone (friends, family, coworkers, others) who has HIV or AIDS or has died of AIDS?" with response options "yes" and "no." We also asked participants to report on the number of sexual partners that they had in the past 12 months (a marker of recent HIV risk) with the question, "During the last 12 months, with how many different partners did you have sex (vaginal or anal)?”

Predictors: Church-Related HIV Stigmatizing Attitudes and HIV Discussions. To assess HIV stigmatizing attitudes among congregants, we created an item for the study that was based on prior stigma-related scales designed to assess stigma using 
hypothetical situations" ${ }^{52}$ : Suppose you attended a church and found out that some of the members were HIV-positive. How would you feel about attending that church?" Response items were $1=$ very comfortable, 2 =somewhat comfortable, $3=$ uncertain, $4=$ somewhat uncomfortable, and $5=$ very uncomfortable.

We also created three items to assess the discussion of HIV within the church. Participants were asked, "In the last 6 months, did you discuss the following HIV/ AIDS topics with other people in this church?" and then responded "yes" or "no" for three specific topics: HIV testing, abstinence, and condoms. We selected these topics based on our previous case study research, which found that conversations around HIV in church-based settings tended to focus primarily on abstinence, although some congregations also promoted HIV testing (e.g., through health fairs) and discussed (but did not distribute) condoms. ${ }^{53}$

\section{Statistical Analysis}

We first examined descriptive statistics of the sample as a whole to characterize the different congregations examined. We then conducted multivariate linear and logistic regressions predicting willingness for church-related HIV testing and ever having been tested for HIV, respectively, with the complete set of sociodemographic, HIV-related cues to action, HIV stigmatizing attitudes, and HIV discussion variables as predictors, based on research reviewed above suggesting that these variables are related to HIV testing. To control for clustering at the church level, both multivariate models also included indicators for church as fixed effects (note that, because we only had five clusters, random effects or normal survey cluster adjustments could not be applied; thus, it was necessary to use fixed effects of church to account for the similarity of responses expected within churches and to ensure that standard errors for other predictors were not underestimated). Individuals who reported that they had previously tested positive $(n=21)$ and USborn Latinos who reported low English proficiency $(n=8)$ were excluded from analyses. In order to aid in interpretability of coefficients, our continuous outcome (willingness to be tested in church) and continuous and ordinal predictors (age, education, annual household income, number of partners in the last 12 months, congregational HIV stigma) were standardized to mean $=0$ and $\mathrm{SD}=1$ for use in modeling.

Missing data, ranging from 1-10\% per item, were imputed with sequential regression multivariate methods using IVEware $0.2 .{ }^{54}$ We created five imputed datasets for the baseline survey and used standard rules for aggregating results across datasets. ${ }^{55}$ Sensitivity analyses were performed to assess the appropriateness of the linear model for willingness to be tested at church. Specifically, we fit ordinal models and found that inferences did not differ; thus, to ease interpretability, we present results from the linear regression models, which show standardized effects between the predictors and willingness to be tested at church.

\section{RESULTS}

\section{Participant Characteristics}

A total of 1211 congregants completed surveys, including 418 African Americans, 198 US-born Latinos, 196 foreign-born Latinos with high English proficiency, and 399 foreign-born Latinos with low English proficiency (see Table 1). Overall, 64 \% of participants were women, the average age of the sample was $40.4(\mathrm{SD}=15.1)$, 


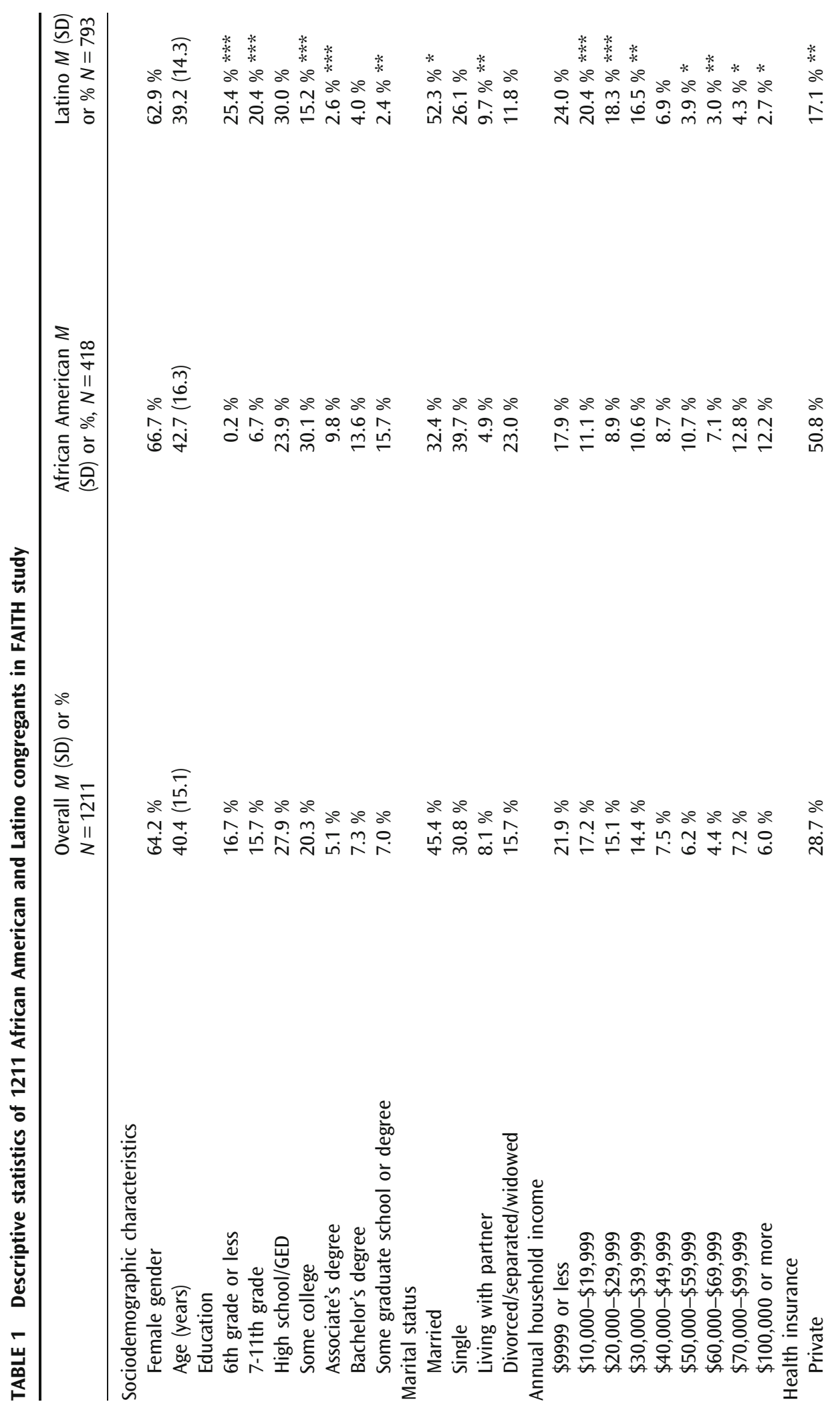




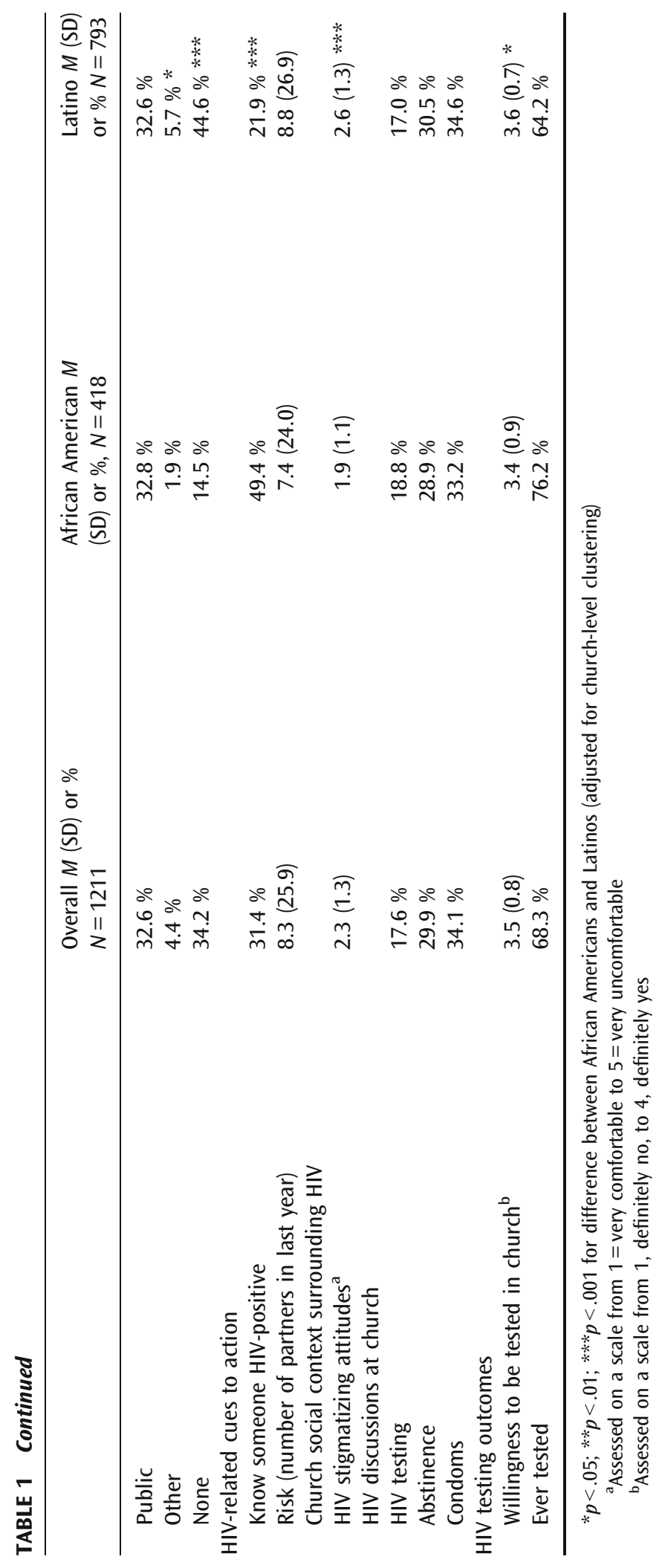


and over half of the sample had annual household incomes below \$30,000. About a third had less than a high school education, and $45.4 \%$ were married. About a third $(32.6 \%)$ had public health insurance, $28.7 \%$ had private insurance, and over a third $(34.2 \%)$ had no health insurance. African Americans and Latinos showed significant differences on education, income, and marital status. A higher percentage of Latinos than African Americans reported lower levels of education, with over a quarter of Latinos, versus less than $1 \%$ of African Americans, having a sixth grade education or less $(p<.001)$. A greater percentage of Latinos reported low annual household income; for example, over a fifth of Latinos, versus over a tenth of African Americans, reported being in the $\$ 10,000-\$ 19,999$ category $(p<.001)$, whereas about $3 \%$ of Latinos versus over $12 \%$ of African Americans reported being in the highest category $(>\$ 100,000 ; p<.05)$. A higher percentage of Latinos were married $(p<.05)$ or living with a partner $(p<.01)$.

In terms of HIV-related cues to action, $31.4 \%$ knew someone with HIV, and African Americans were more likely to know someone with HIV than were Latinos $(p<.001)$. The median number of sexual partners in the past 12 months was 1 . Participants showed relatively low average levels of stigmatizing attitudes around HIV $[M=2.3$ (1.3), which corresponded to "somewhat comfortable" on the five-point scale], and African Americans showed lower HIV stigma than did Latinos $(p<.001)$. Substantial percentages had discussed HIV with other congregants: $17.6 \%$ said that they had discussed HIV testing with others in church, $29.9 \%$ said that they had discussed abstinence, and $34.1 \%$ said that they had discussed condoms.

Participants were generally willing to be tested for HIV at church $[M=3.5(0.8)$; close to "definitely yes" on the four-point scale]. A total of $68.3 \%$ had ever been tested. African Americans showed lower willingness to be tested in church $(p<.01)$.

\section{Multivariate Models Predicting Willingness to be Tested at Church}

Multivariate models indicated that participants showed higher willingness to be tested for HIV at their church if they were younger $(b=-0.12 \mathrm{SD}$ change in willingness to be tested for a one SD increase in age), had lower stigmatizing attitudes in response to a hypothetical HIV-positive congregant $(b=-0.10$ for a one SD increase in stigma), and had discussed condoms with other congregants $(b=0.18)$ (see Table 2). Foreign-born Latinos with low English proficiency were more willing to be tested at church than were African Americans $(b=0.34)$.

\section{Multivariate Models Predicting HIV Testing in Lifetime}

Gender, age, race/ethnicity, marital status, knowing someone who had HIV or had died of AIDS, and recent discussions of HIV testing, abstinence or condoms in church were all associated with HIV testing behavior (see Table 2). Specifically, a higher likelihood of ever being tested was observed among participants who were female (OR =1.53), as well as those who knew a friend or family member with HIV or who died of AIDS (OR =1.50). Moreover, those who had recently discussed HIV testing $(\mathrm{OR}=2.05)$ or condoms $(\mathrm{OR}=1.55)$ in church had a higher likelihood of ever having been tested. A lower likelihood of ever being tested for HIV was related to being older $(\mathrm{OR}=0.75)$, Latino $(\mathrm{OR}=0.37$ for US-born Latinos of high English proficiency compared to African Americans; and OR = 0.51 for foreign-born Latinos of low English proficiency vs. African Americans), and single (vs. married; $\mathrm{OR}=0.61$ ). Those who had recently discussed abstinence in church had a lower likelihood $(\mathrm{OR}=0.49)$ of ever being tested for HIV. 
TABLE 2 Multivariate regressions predicting willingness to be tested for HIV in church and HIV testing in lifetime with sociodemographic characteristics, HIV-related cues to action, and church-related social climate surrounding HIV among 1211 congregants

\begin{tabular}{|c|c|c|}
\hline Predictors & $\begin{array}{l}\text { Willingness to test for } \\
\text { HIV in church adjusted } \\
\text { beta (95\% confidence } \\
\text { interval) }\end{array}$ & $\begin{array}{l}\text { Ever tested for HIV } \\
\text { adjusted odds ratio } \\
(95 \% \text { confidence } \\
\text { interval) }\end{array}$ \\
\hline \multicolumn{3}{|l|}{ Sociodemographic characteristics } \\
\hline Female gender & $0.00(-0.12,0.11)$ & $1.51(1.12,2.02)^{* *}$ \\
\hline Age & $-0.12(-0.21,-0.04)^{* *}$ & $0.75(0.62,0.90)^{* * *}$ \\
\hline Education & $-0.02(-0.10,0.06)$ & $1.20(1.00,1.44)^{*}$ \\
\hline \multicolumn{3}{|c|}{ Race/ethnicity/english proficiency/nativity (reference = African American) } \\
\hline Latino (US-born) & $-0.07(-0.30,0.16)$ & $0.38(0.21,0.70)^{* *}$ \\
\hline $\begin{array}{l}\text { Latino (foreign-born, high english } \\
\text { proficiency) }\end{array}$ & $0.21(-0.04,0.46)$ & $0.57(0.30,1.09)$ \\
\hline $\begin{array}{l}\text { Latino (foreign-born, low english } \\
\text { proficiency) }\end{array}$ & $0.35(0.11,0.59)^{* *}$ & $0.51(0.27,0.97)^{*}$ \\
\hline \multicolumn{3}{|l|}{ Marital status $($ reference $=$ married $)$} \\
\hline Single & $0.01(-0.16,0.18)$ & $0.57(0.38,0.86)^{* *}$ \\
\hline Living with partner & $0.03(-0.19,0.25)$ & $0.90(0.50,1.61)$ \\
\hline $\begin{array}{l}\text { Divorced/separated/ } \\
\text { widowed }\end{array}$ & $0.04(-0.16,0.24)$ & $0.87(0.58,1.31)$ \\
\hline Annual household income & $-0.10(-0.18,-0.02)^{*}$ & $0.88(0.72,1.06)$ \\
\hline \multicolumn{3}{|l|}{ Health insurance (reference $=$ private) } \\
\hline Public & $-0.11(-0.28,0.06)$ & $1.09(0.74,1.62)$ \\
\hline Other & $-0.24(-0.57,0.09)$ & $0.89(0.42,1.85)$ \\
\hline None & $0.02(-0.15,0.20)$ & $0.89(0.58,1.34)$ \\
\hline \multicolumn{3}{|l|}{ HIV-related cues to action } \\
\hline Know someone HIV-positive & $0.00(-0.14,0.13)$ & $1.52(1.09,2.12) *$ \\
\hline Risk (number of partners in last year) & $-0.01(-0.09,0.07)$ & $1.19(0.93,1.53)$ \\
\hline \multicolumn{3}{|l|}{ Church social context surrounding HIV } \\
\hline $\begin{array}{l}\text { HIV stigmatizing attitudes } \\
\text { HIV discussions at church }\end{array}$ & $-0.10(-0.16,-0.04)^{* * *}$ & $0.94(0.82,1.09)$ \\
\hline HIV testing & $0.04(-0.14,0.23)$ & $2.02(1.30,3.15) * *$ \\
\hline Abstinence & $-0.13(-0.29,0.04)$ & $0.49(0.34,0.71) * * *$ \\
\hline Condoms & $0.18(0.02,0.33)^{*}$ & $1.54(1.08,2.21)$ * \\
\hline
\end{tabular}

Both regressions controlled for church clustering. Multivariate linear regression was used to test predictors of "willing to test for HIV in church," and multivariate logistic regression was used to test predictors of "ever tested for HIV."

${ }^{*} p<.05 ; * * p<.01 ; * * * p<.001$

\section{DISCUSSION}

In this study of African American and Latino church congregants, we found that key sociodemographic factors, HIV-related cues to action, HIV stigmatizing attitudes, and discussions in church about HIV were associated with willingness to be tested at church and HIV testing behavior in general. Most prior research on HIV prevention in congregations has not examined Latino churches as well as African American ones, or explored stigmatizing attitudes and conversations about HIV that occur in church settings as correlates of HIV testing receptivity and behavior. Prior research 
has instead focused on sociodemographic variables and HIV-related cues to action, primarily in general populations. As a result, less is known about the impact of HIVrelated attitudes and discussions in church settings.

Several sociodemographic factors were associated with the HIV testing outcomes. For example, individuals who were younger were more willing to being tested at church. Immigrant Latinos with low English proficiency were more willing to be tested at church than were African Americans. Although this finding has not be demonstrated previously for HIV testing, it is consistent with research indicating that Spanish-speaking Latino women were more receptive to mobile mammography at church than were English-speaking women. ${ }^{51}$ Immigrants may feel uncomfortable in traditional healthcare settings due to language barriers and concerns about being reported if they are undocumented, and also may have less access to testing due to a lack of insurance coverage. ${ }^{56}$ Church-based testing, in a culturally acceptable setting, is an underutilized resource that can overcome language and trust barriers, and thus may provide one way to reach these at-risk populations. ${ }^{57}$

Our most novel results concern the church-related predictors of HIV stigmatizing attitudes and HIV-related discussions among congregants. Participants who expressed discomfort with attending church alongside HIV-positive congregants were less willing to get tested at church; and participants who had conversations with other people at the church about abstinence were less likely to have been tested. Conversely, talking with other people at the church about HIV testing and condoms was associated with a higher likelihood of testing. A supportive church environment has been shown to positively influence individuals' health behaviors (such as physical activity). ${ }^{58,59}$ A supportive church environment regarding discussions about prevention, including HIV testing and condom use, could encourage individual testing behavior. Churches are viewed as credible community sources, and as shown here, may positively influence individual-level HIV prevention behaviors. However, talking about abstinence alone, which has been shown to be an ineffective HIV prevention strategy for decreasing the likelihood of condomless sex, the number of sexual partners, or the probability of early coital debut in high-income countries, ${ }^{60}$ may also discourage testing. Future research on understanding church-related barriers to and facilitators of HIV testing could extend our work by qualitatively examining the content of conversations about HIV within the church setting, to explore the mechanisms by which conversations about abstinence might discourage testing and conversations about testing might encourage it. For example, conversations about abstinence may tend to accompany (or evoke) a more conservative religious framing of HIV as a "punishment for sin," whereas conversations about testing encourage a framing of HIV as a public health issue. ${ }^{61}$

Our findings have implications for intervention, suggesting that the social context of the church can have an impact on congregants' behaviors. Changes to the church environment, including to the dialogue around HIV, may have a rippling effect on the congregation. Prior research suggests that popular opinion leaders who engage peers in informal conversations about HIV prevention can help to reduce community-level HIV stigma. ${ }^{62,63}$ Such diffusion of HIV prevention messages may be more efficient in relatively closed communities, such as faith-based organizations, where information of interest to the congregation may spread quickly. Thus, use of a popular opinion leader approach—perhaps by reaching congregants through formal and informal church leaders-may be promising, especially if messages designed to change norms around HIV testing are combined with greater availability of testing in the community or at the church. ${ }^{48,64}$ 
Although the present study included a relatively large proportion of congregants across churches as compared to other studies, our research also had some limitations, including the use of a select, non-random sample of churches and congregants. Although the limited set of churches we were able to include in this pilot study was drawn from a broader pool of churches, several churches did not respond to requests for screening or refused to participate, potentially because of lower acceptance of HIV-related activities. Thus, our sample may have been biased toward churches with lower levels of HIV stigma or a greater openness to HIVrelated activities. In addition, because the present analysis of baseline data is crosssectional, the directions of the relationships are unclear and causality cannot be inferred, especially because we did not assess the content or timing of conversations about testing or abstinence. For example, conversations about testing could occur both before and after a testing experience, and their content at these different timepoints may be different and potentially have distinct effects. Moreover, the question used to assess discussions about HIV with other people at church could be interpreted as conversations physically occurring at church, or conversations occurring with congregants in other settings; in addition, this item did not assess the quality of such discussions. Further, since data collection was conducted at church, congregants may have been inclined to under-report risk behaviors (e.g., unmarried sexual activity) and over-report HIV-related discussions. We minimized this possibility by having non-church members administer the survey and handle confidential materials, with a strict data safeguarding plan.

In sum, our study suggests that church-related factors, including the church's social climate surrounding HIV, are related to congregants' HIV testing behaviors. Our results do not illuminate whether this association reflects a causal influence of social climate on HIV testing behaviors. Future research can examine whether churches that promote and sustain open dialogue around HIV, including discussions about testing and condoms, activate congregants to be more receptive to getting tested for HIV in general, as well as at the church.

\section{ACKNOWLEDGMENTS}

This study was supported by Grant Number 1 R01 HD050150 from the Eunice Kennedy Shriver National Institute for Child Health and Human Development (NICHD; K Derose, PI). We are grateful to members of the study's Community Advisory Board, especially the co-chairs Michael Mata, MA, MCP, MDiv, and Clyde W. Oden, OD, MPH, MBA, MDiv. We also thank Karen R. Flórez, DrPH, $\mathrm{MPH}$, Frances Aunon, BA, and Alexandria Smith MPH, for their contributions to the analysis team, and Jennifer Hawes-Dawson, BA, Alexandria Felton, MPH, and Blanca X. Domínguez, MPH for help with data collection. In addition, we would like to express our gratitude to the churches and individuals who participated.

\section{REFERENCES}

1. Centers for Disease Control and Prevention. Vital signs: HIV prevention through care and treatment - United States. Morb Mortal Wkly Rep. 2011; 60(47): 1618-1623.

2. Centers for Disease Control and Prevention. HIV in the United States: The stages of care. Atlanta, GA 2012. 
3. Centers for Disease Control and Prevention. Late HIV testing - 34 states, 1996-2005. Morb Mortal Wkly Rep. 2009; 58(24): 661-665.

4. Centers for Disease Control and Prevention. Revised recommendations for HIV testing of adults, adolescents, and pregnant women in health-care settings. Morb Mortal Wkly Rep. 2006; 55: 1-17.

5. Boulware LE, Cooper LA, Ratner LE, LaVeist TA, Powe NR. Race and trust in the health care system. Public Health Rep. 2003; 118(4): 358-365.

6. LaVeist TA, Nickerson KJ, Bowie JV. Attitudes about racism, medical mistrust, and satisfaction with care among African American and white cardiac patients. Med Care Res Rev. 2000; 57(Suppl 1): 146-161.

7. Hammond WP, Matthews D, Corbie-Smith G. Psychosocial factors associated with routine health examination scheduling and receipt among African American men. J Natl Med Assoc. 2010; 102(4): 276-289.

8. Thompson HS, Valdimarsdottir HB, Winkel G, Jandorf L, Redd W. The Group-Based Medical Mistrust Scale: psychometric properties and association with breast cancer screening. Prev Med. 2004; 38(2): 209-218.

9. Bogart LM, Thorburn S. Are HIV/AIDS conspiracy beliefs a barrier to HIV prevention among African Americans? J Acquir Immune Defic Syndr. 2005; 38(2): 213-218.

10. The Washington Post, The Henry J. Kaiser Family Foundation. 2012 Summary and Chartpack: The Washington Post/Kaiser Family Foundation 2012 Survey of Americans on HIV/AIDS. 2012 Washington, D.C.

11. Dorr N, Krueckeberg S, Strathman A, Wood MD. Psychosocial correlates of voluntary HIV antibody testing in college students. AIDS Educ Prev. 1999; 11(1): 14-27.

12. de Wit JB, Adam PC. To test or not to test: psychosocial barriers to HIV testing in highincome countries. HIV Med. 2008; 9(Suppl 2): 20-22.

13. Adam PC, de Wit JB. A concise overview of barriers and facilitators of HIV testing: directions for future research and interventions. Utrecht, The Netherlands: Institute for Prevention and Social Research; 2006.

14. Murray K, Oraka E. Racial and ethnic disparities in future testing intentions for HIV: United States, 2007-2010: results from the National Health Interview Survey. AIDS Behav. 2014; 18(7): 1247-1255.

15. Centers for Disease Control and Prevention. CDC Fact Sheet: HIV Testing in the United States. Atlanta, GA: Centers for Disease Control and Prevention; 2013.

16. The Henry J. Kaiser Family Foundation. HIV testing in the United States. Melno Park, CA: The Henry J. Kaiser Family Foundation; 2014.

17. Centers for Disease Control and Prevention. Vital signs: HIV infection, testing, and risk behaviors among youths-United States. Morb Mortal Wkly Rep. 2012; 61(47): 971-976.

18. Robinson KT, Sanders SA, Boyd JL. High-risk HIV minorities in the United States: who gets tested and where? Am J Health Behav. 2012; 36(3): 348-359.

19. Carter MW, Kraft JM, Hatfield-Timajchy K, Hock-Long L, Hogben M. STD and HIV testing behaviors among black and Puerto Rican young adults. Perspect Sex Reprod Health. 2011; 43(4): 238-246.

20. Benavides-Torres RA, Wall KM, Nunez Rocha GM, Onofre Rodriguez DJ, Hopson L. Factors associated with lifetime HIV testing in Texas by race/ethnicity. Open AIDS J. 2012; 6: 232-238.

21. Swenson RR, Rizzo CJ, Brown LK, et al. Prevalence and correlates of HIV testing among sexually active African American adolescents in 4 US cities. Sex Transm Dis. 2009; 36(9): 584-591.

22. Mimiaga MJ, Reisner SL, Bland S, et al. Health system and personal barriers resulting in decreased utilization of HIV and STD testing services among at-risk black men who have sex with men in Massachusetts. AIDS Patient Care STDS. 2009; 23(10): 825-835.

23. Ojikutu B, Nnaji C, Sithole J, et al. All black people are not alike: differences in HIV testing patterns, knowledge, and experience of stigma between U.S.-born and non-U.S.born blacks in Massachusetts. AIDS Patient Care STDS. 2013; 27(1): 45-54. 
24. Janz NK, Becker MH. The health belief model: a decade later. Health Educ Q. 1984; 11(1): 1-47.

25. Nunn A, Eng W, Cornwall A, et al. African American patient experiences with a rapid HIV testing program in an urban public clinic. J Natl Med Assoc. 2012; 104(1-2): 5-13.

26. Fernandez MI, Collazo JB, Bowen GS, Varga LM, Hernandez N, Perrino T. Predictors of HIV testing and intention to test among Hispanic farmworkers in South Florida. J Rural Health. 2005; 21(1): 56-64.

27. Chen N, Erbelding E, Yeh HC, Page K. Predictors of HIV testing among Latinos in Baltimore City. J Immigr Minor Health. 2010; 16(6): 867-874.

28. Mitchell JW, Horvath KJ. Factors associated with regular HIV testing among a sample of US MSM with HIV-negative main partners. J Acquir Immune Defic Syndr. 2013; 64(4): 417-423.

29. Oster AM, Russell K, Wiegand RE, et al. HIV infection and testing among Latino men who have sex with men in the United States: the role of location of birth and other social determinants. PLoS One. 2013; 8(9): e73779.

30. Craig SL, Beaulaurier RL, Newman FL, De La Rosa M, Brennan DJ. Health and cultural determinants of voluntary HIV testing and counseling among middle-aged and older Latina women. J Women Aging. 2012; 24(2): 97-112.

31. Castillo-Mancilla J, Allshouse A, Collins C, Hastings-Tolsma M, Campbell TB, Mawhinney S. Differences in sexual risk behavior and HIV/AIDS risk factors among foreign-born and US-born Hispanic women. J Immigr Minor Health. 2012; 14(1): 89-99.

32. Gilbert PA, Rhodes SD. HIV testing among immigrant sexual and gender minority Latinos in a US region with little historical Latino presence. AIDS Patient Care STDS. 2013; 27(11): 628-636.

33. Glasman LR, Weinhardt LS, DiFranceisco W, Hackl KL. Intentions to seek and accept an HIV test among men of Mexican descent in the Midwestern USA. AIDS Care. 2010; 22(6): 718-728.

34. Ashton CM, Haidet P, Paterniti DA, et al. Racial and ethnic disparities in the use of health services. J Gen Intern Med. 2003; 18(2): 146-152.

35. Ortega AN, Fang H, Perez VH, et al. Health care access, use of services, and experiences among undocumented Mexicans and other Latinos. Arch Intern Med. 2007; 167(21): 2354.

36. DeHaven MJ, Hunter IB, Wilder L, Walton JW, Berry J. Health programs in faith-based organizations: are they effective? Am J Public Health. 2004; 94(6): 1030-1036.

37. Derose KP, Mendel PJ, Kanouse DE, et al. Learning about urban congregations and HIV/ AIDS: community-based foundations for developing congregational health interventions. J Urban Health. 2010; 87(4): 617-630.

38. Chaves M, Anderson S, Byassee J. American Congregations at the Beginning of the 21st Century. Available at: http://www.soc.duke.edu/natcong/Docs/NCSII_report_final.pdf. Accessed June 6, 2014.

39. Centers for Disease Control and Prevention. Cases of HIV infection and AIDS in urban and rural areas of the United States, 2006. Department of Health and Human Services. Available at: http://www.cdc.gov/hiv/pdf/statistics_2008_HIV_Surveillance_Report_vol_13_no2.pdf. Accessed November 17, 2013.

40. Centers for Disease Control and Prevention. Today's HIV/AIDS epidemic. Available at: http://www.cdc.gov/nchhstp/newsroom/docs/HIVFactSheets/TodaysEpidemic-508.pdf. Accessed November 28, 2013.

41. Williams MV, Haas A, Griffin BA, et al. Predictors of congregational HIV programs: similarities and differences compared with other health programs. Am J Health Promot. Forthcoming 2014

42. Berkley-Patton J, Moore EW, Hawes SM, Thompson CB, Bohn A. Factors related to HIV testing among an African American church-affiliated population. AIDS Educ Prev. 2012; 24(2): 148-162.

43. Williams T, Pichon LC, Latkin CA, Davey-Rothwell M. Practicing what is preached: congregational characteristics related to HIV testing behaviors and HIV discussions among Black women. J Community Psychol. 2014; 42(3): 365-378. 
44. Weinreb AA. Change and instability: A multilevel analysis of AIDS-related conversational networks among Malawian women. Demogr Res. 2003; Special Collection 1(Article 12):373-396.

45. Kaler A. AIDS-talk in everyday life: the presence of HIV/AIDS in men's informal conversation in Southern Malawi. Soc Sci Med. 2004; 59(2): 285-297.

46. de Paoli MM, Manongi R, Klepp KI. Factors influencing acceptability of voluntary counselling and HIV-testing among pregnant women in Northern Tanzania. AIDS Care. 2004; 16(4): 411-425.

47. Prati G, Mazzoni D, Zani B. The influence of knowing someone with HIV/AIDS on preventive behaviors in Italy. AIDS Care. 2014; 26(3): 292-296.

48. Derose KP, Bogart LM, Kanouse DE, et al. An intervention to reduce HIV-related stigma in partnership with African American and Latino churches. AIDS Educ Prev. 2014; 26(1): 28-42.

49. City of Long Beach Department of Health and Human Services. HIV/AIDS monitoring report. Available at: http://www.longbeach.gov/civica/filebank/blobdload.asp?BlobID=37387. Accessed November 18, 2013.

50. Centers for Disease Control and Prevention. Estimated HIV incidence in the United States, 2007-2010. HIV surveillance supplemental report, 17(No. 4). Available at: http:// www.cdc.gov/hiv/surveillance/resources/reports/2010supp_vol17no4/. Accessed November 18, 2013

51. Derose KP, Duan N, Fox SA. Women's receptivity to church-based mobile mammography. J Health Care Poor Underserved. 2002; 13(2): 199-213.

52. Berkley-Patton JY, Moore E, Berman M, et al. Assessment of HIV-related stigma in a US faithbased HIV education and testing intervention. J Int AIDS Soc. 2013; 16(3 Suppl 2): 18644.

53. Derose KP, Mendel PJ, Palar K, et al. Religious congregations' involvement in HIV: a case study approach. AIDS Behav. 2011; 15(6): 1220-1232.

54. Raghunathan TE, Lepkowski JM, Hoewyk JPS. A multivariate technique for multiply imputing missing values using a sequence of regression models. Survey Methodology. 2001; 27(1): 85-95.

55. Rubin D. Multiple imputation for nonresponse in surveys. Hoboken, NJ: Wiley; 1987.

56. Prentice JC, Pebley AR, Sastry N. Immigration status and health insurance coverage: who gains? Who loses? Am J Public Health. 2005; 95(1): 109-116.

57. Sutton MY, Parks CP. HIV/AIDS prevention, faith, and spirituality among black/African American and Latino communities in the United States: strengthening scientific faithbased efforts to shift the course of the epidemic and reduce HIV-related health disparities. J Relig Health. 2013; 52(2): 514-530.

58. Baruth M, Wilcox S, Saunders RP, Hooker SP, Hussey JR, Blair SN. Perceived environmental church support and physical activity among Black church members. Health Educ Behav. 2013; 40(6): 712-720.

59. Baruth M, Wilcox S, Condrasky MD. Perceived environmental church support is associated with dietary practices among African-American adults. J Am Diet Assoc. 2011; 111(6): 889-893.

60. Underhill K, Operario D, Montgomery P. Abstinence-only programs for HIV infection prevention in high-income countries. Cochrane Database Syst Rev. 2007; 4, CD005421.

61. Derose KP, Kanouse DE. Faith-based organizations and the framing of HIV/AIDS. In: Miller AN, Rubin DL, eds. Health communication and faith communities. Cresskill, N.J: Hampton Press; 2011:115-141.

62. Young SD, Konda K, Caceres C, et al. Effect of a community popular opinion leader HIV/ STI intervention on stigma in urban, coastal Peru. AIDS Behav. Epub 2010.

63. Li L, Liang LJ, Lin C, Wu Z, Rotheram-Borus MJ. HIV prevention intervention to reduce HIV-related stigma: evidence from China. AIDS. 2010; 24(1): 115-122.

64. Berkley-Patton J, Bowe-Thompson C, Bradley-Ewing A, et al. Taking It to the Pews: a CBPR-guided HIV awareness and screening project with black churches. AIDS Educ Prev. 2010; 22(3): 218-237. 